\title{
Teacher Development in Higher Education in an EFL Context: Why Evaluate and How to Evaluate?
}

\author{
Saeed Jamel Aburizaizah \\ University of Jeddah, Jeddah, Saudi Arabia
}

\begin{abstract}
With the ongoing and increasing demands pertaining to teachers' performance evaluation and professional development plans, it has become necessary to improve the quality of performance. This study aimed at exploring the importance of assessing the instructional performance of EFL language teachers at the English Language Institute at King Abdulaziz University. It also tried to uncover the visible outcomes of the ongoing development. Method of the study consisted of a focus group interview conducted with 15 teachers coming from different educational contexts. Findings, based on a content analysis, revealed that teachers' performance developed and that the observation components helped to raise their awareness of teaching good practices. Recommendations were made to consider such good practices to enhance the teaching and learning of English in an EFL context.
\end{abstract}

Keywords: teacher development, higher education, quality performance, evaluation, teaching practices, observation forms

\section{Introduction}

This study addressed teacher development to support EFL teaching at higher education in a Saudi context and the ways to provide some helpful tips for instructors to improve their skills through interaction, and to encourage self-reflection. Ongoing teacher evaluation for the development and betterment of the learning environment has been given its due importance in research in general, but not in an EFL context, such as Saudi Arabia. Much importance is attributed to teacher self-reflection as a peer observation tool deemed vital for professional development. However, instruction delivery may vary from one teacher to another, since their views of language teaching are different. Such differences could largely affect the process of peer observation and by extension other facets of the learning process, such as assessment. Due to its centrality in educational reform, teacher development has gained a considerable ground in various research studies contending that teacher learning is accountable for teaching and educational system effectiveness and high-standards teacher development (Judah \& Richardson, 2006; Sargent \& Hannum, 2009). To accommodate the varieties and challenges that nowadays classrooms posit, teachers similarly hold responsible for their students' achievement and learning (Florian, 2012). For this reason, through advocating teacher development that can be exemplified in some collaborative and self-reflexive strategies, teachers are encouraged to ponder upon their classroom practices and explore areas of improvement and teacher learning. In fact, in a reflective paradigm, teachers seek not only to examine their previous actions, but they equally tend to elicit knowledge from their teaching contexts (Yeboah \& James, 2012). More precisely, they form their curriculum understanding, adjust their 
teaching and learning theories, and constantly re-conceptualise as well as develop their roles as teachers (Desimone, 2009; Koutselini, 2008). Accordingly, the quality and the impact of teacher development on students can be developed along a knowledge and evaluation base teachers tend to entertain, and via a plethora of methods.

\section{Theoretical Background}

The methods teachers have at their disposition enshrine individual and collaborative techniques and are introduced in and shaped by a variety of situations. Instantly, individual teacher development may encompass practice-based strategies, where teachers implement particular instructional methods and aim at meaningful impact on their professional development and student learning (Harris et al., 2012). This means that some development practices are teacher-based initiatives, yet they are integrated in an intricate educational and societal system where assimilation is not an anticipated merit (Mirra \& Morrell, 2011). Yet, such a fact does not deny the effectiveness of this individual practice, nor does it diminish the significance of teacher development and the manner utilised to attain advanced levels of teacher scholarship (Loughran, 2014). Teacher-based initiatives offer insights into teacher autonomy and perceptions of teacher learning detected in diverse educational systems and accomplished through diverse strategies.

In outlining the individual methods teachers may refer to for professional development reasons, it is important to attend to some variables that are critical to this process: teacher autonomy and teacher needs. Teacher development practices are singularly connected with their autonomy as active and self-effective teachers (Hiver, 2013; Hokka \& Etelapelto, 2014). Their roles as teachers and knowledge transmitters define their professional development preferences and shape their individual and collaborative propensities (Dierking \& Fox, 2012; Gao \& Xu, 2014). In fact, Dierking and Fox research findings (2012) underscore the fact that teacher agency in professional development is mandatory for teacher education to be an empowerment and effectiveness instrument. Tracing a professional identity is, therefore, contingent upon the dynamics of teacher agency in professional development (Williams, 2014). In the same vein teacher development variables, the question of the centrality of teacher needs is raised. Any professional development cannot be divorced from individual needs that teachers have. They, in effect, emanate from their teachings contexts, where the focus is on teaching procedures, curricular matters, and student performance (Hokka \& Etelapelto, 2014). Teachers need to meet their instructional objectives, to explicate these goals to their students, to analyse their classroom actions, and to monitor student achievement. For this reason, teacher professional development techniques are, to a great extent, dictated by their emerging as well as constant needs (Tunney, Goldsmith, Seago, \& Van Es, 2014).

At the collaborative plane of professional development, it is crucial to address the growing practice of forming and acting within professional development communities. In the process of a radical departure from teacher isolation, the advent of professional learning community foundation and collegiality among teachers to further teacher education are detected (Lieberman \& Mace, 2010). This practice highlights not only collaborative professional development plans and issues, it similarly provides insights about teachers' processes of meaning-creation and collective reflection on actual teaching practices and challenges they report (Koutselini, 2008). In these professional learning communities, teachers are provided with joint grounds to engage in predefined teacher learning situations, to identify areas of teachers' needs, and to transform their perceptions of professional development into concrete actions (Swars, Meyers, Mays, \& Lack, 2009). 
Furthermore, these communities that can be sometimes school-based supply teachers with alterative professional development routes they could not figure in their individual strategies (Cuddapah \& Clayton, 2011). In fact, with the centrality of the community component, teacher networking could be used to accomplish mentoring practices achieved mainly through observation sessions and corroborated via interviews and group discussions.

In their professional development practices, teachers identify their learning styles as professionals. As these styles range from the individual to the collaborative style, a suitable environment could accommodate both. In some research studies, teachers embarked on issuing reflective journals to verify the effectiveness of their practice and they passed these personal writings to be evaluated by peers (Cowan \& Westwood, 2006). In this respect, reported instructional and classroom experiences were compiled and evaluation comments were subjective and objective. In other research studies, to enhance the quality of professional development practices in their individual and collaborative modes, collaborative discussions enriched by reading as an individual technique were investigated. The interconnectedness between both aspects led to teachers engaging in transformative knowledge process and to supporting the collaborative learning and common values teachers sought. More than this, professional development programs could be informed by such collaborative and individual practices to specify the agenda of teacher education and to address authentic challenges and gaps teachers may face in their classrooms (Erlam, 2015).

Henderson and Rosenthal (2006) and Tomlinson (2003) defined teacher development as conscious procedures for raising teachers' awareness about their current teaching practices, and specify ways to transfer teachers' learning to their actual teaching contexts. It is an opportunity for teachers to theorize from practice (Edge, 2001). In the same vein, Freeman and Freeman (2004) argue that this development is a result of knowledge building, achieved via multi-faceted engagement with experience, reflection and collaboration. Over time, the teaching process and the teachers' reactions to various factors related to this process can alter and improve teachers' knowledge (Barduhn, 2002). Therefore, the context in which teachers work and the experience they accumulate usually lead to sustained development (Richards, 2001). In this regard, raising awareness could be made possible through reflection that is a pre-requisite of development. For instance, whether pre- or in-service, teachers most often interpret the development programs they have experienced. The reflexive inquiry process and exploratory practice create an opportunity for ongoing development. Therefore, for teachers to become aware of their practice and be able to influence and invest their knowledge and experience, they should be encouraged to engage in reflexive individual and collaborative dialogues. It has also been suggested that novice teachers could integrate with more experienced ones to enhance their practice. McMeniman, Cumming, Wilson, Stevenson, and Sim (2003) state that the more teachers dwell in their practice, the better they will be at monitoring it, making concrete decisions and responding to the changing learners' needs, while the opposite is the case with less reflective teachers.

Interestingly enough, peer observation has become an integral developmental instrument in many higher education institutions. It is implemented to ensure accountability and boost the teaching and learning process through personal reflection. It supplies teachers with the opportunity to update their professional knowledge skills and improve their teaching, which can lead to improving learners' achievement (Hammersley-Fletcher \& Orsmond, 2005). Teachers take turns observing each other classes, reflecting on and discussing teaching practices and approaches. Recent literature on peer observation has advocated the integration of summative (to 
provide a clearer picture of instructors' quality) with formative evaluation (to help instructors improve praxis) (Bernstein, 2008). Peer observation has different usages: (1) to build a holistic view of an instructor's teaching quality; (2) to refine interpersonal skills through the exchange of insights and enhancing teachers' personal skills; and (3) to usher a method of self-reflection and a demonstration of good teaching praxis (Hammersley-Fletcher \& Orsmond, 2004).

Three common models of peer observation are outlined by Gosling (2002). In the first model, a supervisor assumes the role of an observer and makes a decision on teachers' promotion or termination of the contract. This model is beyond the scope of this study. In the second model, an expert teacher observes other teachers and provides them with recommendations. In the third model, a peer or a colleague appraises another teacher for awareness-raising in a non-judgmental way. Models 2 and 3 constitute the core of the study. To evaluate the instructors' performance quality, universities and institutions worldwide employ both formative and summative assessment tools. According to a survey conducted by Seldin (1998), 40.3\% of universities and colleges have utilized peer evaluation and classroom observation techniques along with grading systems for faculty assessment (p. 6).

Additionally, in order to maximize the benefit of peer observation, the observer should possess the skills needed to provide constructive feedback, while the observed must be willing to be reflective on his or her own practice. According to Dörnyei, Csizér, and Németh (2006), teacher development programs should challenge teachers' cognitive ability through reflection. This type of practice raises teachers' awareness and, therefore, increases their motivation to create an environment conducive to learning. In this way, peer observation, which is based on promoting self-reflection and encouraging the creation of a supportive and receptive climate for change, facilitates the process of teacher development and evaluation and, thus, benefits the program in its entirety.

According to Erickson and Lanning (2014), for a teaching lesson to be deemed successful three domains need to be considered: content, pedagogy, and relationships. He explained that an effective teacher should be competent in the subject he is teaching, have the skills and the teaching methods necessary to deliver knowledge to learners in a way they can understand, and be able to connect with learners to build a trusting and cooperative learning atmosphere. Kumaravadivelu (2006) divides in-classroom teaching practice into three stages: diagnosis, treatment, and assessment. Unlike other teaching methods, Kumaravadivelu's model opens up opportunities for teachers to work with different learners' needs. The diagnosis stage is based on experimentation, and is a stage in which a teacher usually works on understanding his learners, then treats their needs with the most appropriate pedagogical techniques. Finally, the teacher assesses the outcomes of the process in order to develop the techniques (Aburizaizah, 2013). To conceptualize the process of interaction between teachers and students, Danielson and McGreal (2000) propose a framework for teaching (FfT) which includes a comprehensive observation form. The main dimension of the FfT framework is the classroom environment, inclusive of respect as well as rapport, and managing learners' behavior and classroom procedures. Another dimension is instruction, where teachers have to demonstrate knowledge of content and pedagogy, the ability to use questioning techniques, the ability to engage students, and the ability to communicate with learners. Another framework is the Protocol for Language Arts Teaching Observation (PLATO) developed at Stanford by Grossman et al. (2010). The PLATO has four main parts: (1) disciplinary demands of classroom talk and activity; (2) instructional scaffolding; (3) representation and use of content; and 
(4) attention to the classroom environment.

\section{The Context of the Study}

In the Saudi context, Arabic is the official language. In some educational settings, it is the medium of instruction up to the university level. However, as a result of global demands, such as technology, science, commerce, and business, English has taken over. English is now regarded as one of the leading subjects in the Saudi educational system, since it has become a mandatory subject from Grade 6 up to the tertiary level. Most Saudis see English as an essential language for the future prosperity of the country in different domains (Aburizaizah, 2014). At all Saudi universities, foundation year (FY) programmes, required for all fresh students coming from high school, are introduced with a great emphasis on English language teaching. This policy has been dictated by the Ministry of Education.

It is important to emphasize the fact that the teaching process is complex, and, therefore, to assess the teaching quality using a scoring system for the various classroom teaching components was challenging, particularly at a relatively small size institute. To this end, teachers were given the opportunity to raise their awareness of the important components of lessons. The components of the proposed observation framework were used as a platform for good teaching practices. Pre- and post-observation discussions, in addition to the observation session feedback, were meant to help teachers develop and make ELINJ a more effective learning environment. The designed observation report concentrated on the following: Planning, Sequencing, Instructions/Evaluations, Motivation/Stimulation, Time Management, Whiteboard and Visuals, Space Management, Enhancement, Summary and Reflection, and finally Language Proficiency. All the framed questions were structured in a broad manner that could assist the observer in reflecting on the instructional skills of the participating instructor.

This study was conducted in a new language institute at a newly developed university, with about 15 English language instructors. Teachers were required to teach 18 contact hours every week. All the 15 instructors were non-native English-speaking expatriates from different countries (Tunisia, India, Pakistan, and Malaysia). For the purpose of this study, the Language Institute is referred to as ELINJ. The English language curriculum used at ELINJ is the Headway Plus series and the mid-term and final exams were all prepared and provided by the curriculum and testing body. Expatriate teachers had to be well trained; otherwise, the university would not hire them or renew their contracts. This made most expatriate teachers feel insecure. Unfortunately, unlike the Saudi instructors, expatriate instructors did not receive any in-service training courses. As a new institute, ELINJ had no evaluation system to evaluate staff performance, or to monitor the quality of the learning process or the outcomes. The only evaluation considered at that time was form filled out by students at the end of each module. However, relying solely on the students' perceptions in evaluating their instructors had its limitations.

In the Saudi educational context, comprehensive and in-depth evaluations are not commonly used. The sociopolitical context was highly influential in bringing about this situation (Aburizaizah, 2013). Evaluation can only take place in concrete terms among those who occupy the same "circle" or level of authority. Outside a specific "circle" the right to voice an opinion on the hiring or firing or the quality of work of those inside it was not granted. Significant changes or improvements in practice do not often take place in an environment like ELINJ, which was controlled and managed according to government policies. In order to encourage systematic self-reflection and peer observation, it was important to explain to all the participating teachers exactly what 
was considered at ELINJ to be effective teaching and to train the teachers in how to use a framework. The purpose of this study was, therefore, to find an alternative approach to evaluation that could be used in this context.

In the light of this study, the following points were taken into consideration. First, the evaluator had a comprehensive understanding of the context and of the evaluation stages required to make a change. He had then to work on raising people's awareness and introduce evaluation to them as a process leading to development, thus encouraging a pattern of positive behavior within the research context. Both formative and summative evaluation techniques were employed, but with more emphasis on the formative techniques. Participants would be assured that the purpose in the early stages would be to develop the evaluation process, and that the issue of accountability would be considered at a later stage.

\section{Scope of the Study}

The scope of this study was to recommend improvements to current teaching practices, and to provide decision makers with solid evidence of teachers' performance quality. The current study adopted the general Kumaravadivelu (2006) framework, in addition to the FfT and PLATO, to design an observation framework to be implemented by teachers at ELINJ. The evaluation process, thus, required a specially designed system, where reliable data on teacher development could be provided. The scope of this study is to turn the ELINJ into a more effective learning environment by involving all instructors in the processes of learning and reflection. The evaluation programme (peer observation and self reflection) was conducted throughout the academic year and the performances of all the 15 teachers who participated were observed and evaluated periodically. The evaluation system was applied to determine whether the framed evaluation improved performance quality and developed new behavioural patterns among instructors. Accordingly, the study aimed to answer the following research questions:

Do formative and summative evaluation procedures lead to a tangible improvement in teachers' performance quality?

Can the current study give rise to new patterns of behaviour among teachers in response to changes in their work environment? If so, to what extent?

\section{Method}

\section{Data Collection Procedure}

To inform these empirical research questions, it was important to develop a system for tracking changes in the quality of performance and behavior of the teachers at ELINJ. The system consisted of a number of activities, all of which were meant to lead to a development in the teachers' performance and encourage them to adopt new patterns of behavior. Initially, all the teachers were required to give a fifteen-minute presentation related to their teaching experience followed by a discussion session about a topic related to English language teaching.

As part of the development system, the teachers were introduced to the observation scheme. They discussed its components before they were scheduled for peer observation sessions. Participants met for a preas well as a post-observation discussion in order to discuss the lesson, agree on the techniques to be used, reflect on the lesson, and build on their experience. The observers were able to compare their sessions and evaluate them according to the differences between earlier and later sessions. Each teacher was observed three 
times during the 15 -week semester, which also meant that each teacher had to observe his peers three times during the semester. However, the third observation session was also attended by an external reviewer (the researcher), who participated in the pre- and post-discussions and in the writing-up of feedback. The last stage of the evaluation system was at the end of the semester: Focus group interviews were conducted with the teachers. They were divided into two groups based on their cultural backgrounds and an effort was made to make the groups homogenous to encourage them to speak; group A had seven members; while group B had eight. For this study, students' evaluation of their teachers was excluded; the concern was that including students' opinions would negatively affect teachers' motivation regarding the process of development.

\section{Data Analysis}

This study gathered primary data in the form of video and audio recordings. The videos were of the classes observed by the teachers and the external evaluator, while the audio recordings were of the focus group interviews with the teachers. The data collected for this study were qualitative through written peer observation forms filled in by the teachers, and audio-recorded focus group interviews with a list of prepared questions. Content analysis was used for the interpretation of the data. The interpretation process involved a review of the "text", and the categorization, coding, and presentation of the data in tabular form. However, the technique used to analyse the content of the observation text was different from that used with the audio transcription. First, the focus group interviews were analysed based on the responses received from each group to pre-designed open discussion questions, along with the important comments made by participants. Themes were developed, as shown in the findings section of this paper, based on the interview questions. The answers obtained from both groups were compared and summarized, and extracts were selected to support the arguments of this research.

The observation form has eleven dimensions, and under each question is a space where the observer could write in an answer. In the analysis of the text, the process was first to check whether or not that dimension formed part of the teacher's lesson and, if it did, whether he had good time management skills. The observer's comments were analysed and categorized according to a three-grade scale (excellent, good, and poor) based on the wording and descriptions given by the observer. Below are the categories/dimensions of the evaluation form:

(1) Planning: Did the teacher define objectives for the lesson? If so, how clearly?

(2) Sequencing: Was the presentation smooth and sequenced? Support your judgment with specific examples.

(3) Instructions/Explanations: Did the teacher explain class material in an understandable way? Provide details.

(4) Motivation/Stimulation: To what degree did the teacher encourage and ensure student participation?

(5) Time management: Did the teacher use class time effectively? How?

(6) White board and visuals: Comment on the teacher's use of the white board and other visual media.

(7) Space management: Do you think the seating arrangement facilitated learning? Describe and comment on the seating plan.

(8) Teacher/Student contact: How sensitive was the teacher to his students' questions and comments? Did he manage to sustain a positive interaction with his students? Comment.

(9) Enhancement: To what extent were students encouraged to practice what they had learned in the lesson 
and to develop accuracy and fluency?

(10) Summary and reflection: Did the teacher summarize the major points of the lesson to ensure student assimilation of the major points of the lesson? Support your answer with specific examples.

(11) Language proficiency: Did the teacher demonstrate a good command of English? Support your opinion with specific examples.

\section{Findings and Discussion}

The research findings revealed that there were improvements in the teachers' performance in addition to teachers' (observers') feedback writing performance over the 15-week period. The analysis of the classroom observation data and the findings were summarized in Figure 1, which showed that the performances of seven out of the fifteen teachers were classified as "poor" by their peers on the first visit. Yet pursuant to the third classroom visit, only one teacher performance was categorized as "poor", and most of the teachers' performances were classified as "good", while two teachers were judged to be "excellent". On the other hand, the data indicated a discrepancy at the level of improvement between the evaluation of peers on the first two visits and on the third observation visit, which was carried out by the external observer (researcher) and a teacher. The performances of nine of the instructors were labelled as "excellent" on the second visit by their peers, while eight of the nine who on the second visit were classified as "excellent", on the third visit were only classified as "good" by the external evaluator. It was assumed that lack of training was the cause of the discrepancy between the teachers (observers') opinions and the opinion of the external evaluator (the researcher).

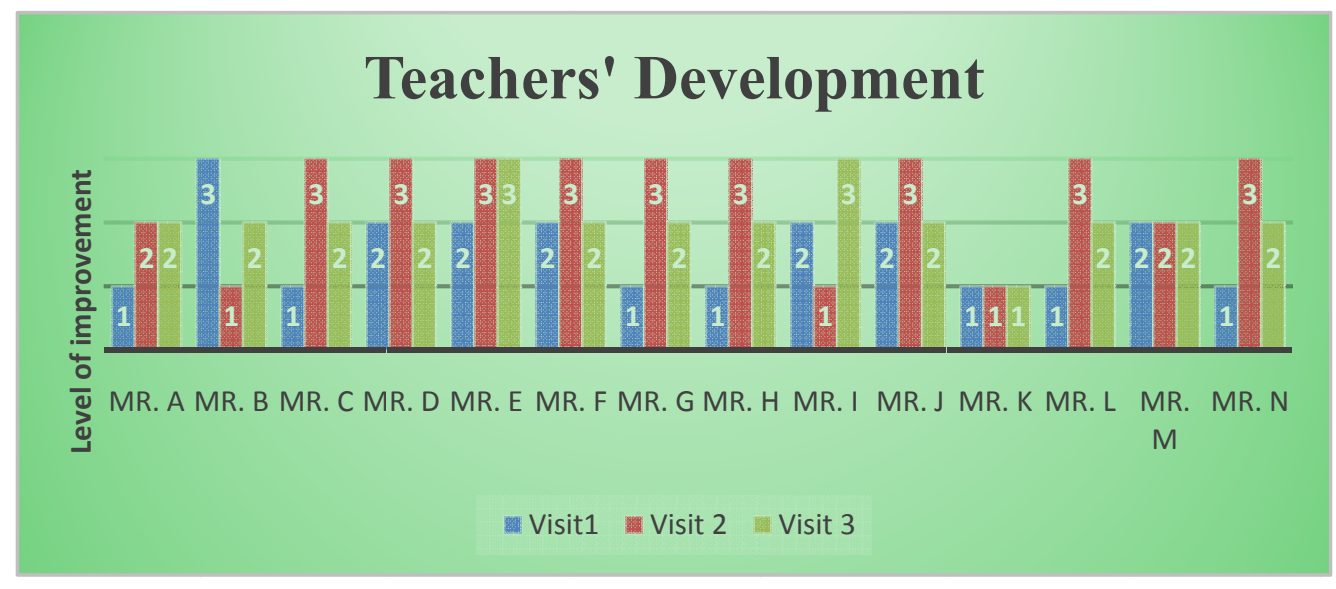

Figure 1. Relevance of the observation sessions for teacher development.

The focus group interview data showed that the instructors were satisfied with the development system. They generally believed that it helped them to reflect on their teaching practice and depart from the daily teaching routine. The interviews showed that the teachers had become more open to discussion and that they were more willing to offer comments on each other's ideas and practice, something which was not common in the working environment at the ELINJ. The presentation sessions helped in establishing a more cooperative working environment. However, the instructors were not happy with the third visit, which was carried out by the external observer; they all thought that visit resulted in undue stress. There was a trust issue, namely that the instructors believed the purpose of the third visit was to evaluate their performance for contract renewal, rather 
than to give formative comments in order to help them develop their practice.

Discussions were based on the data obtained during the performance and development evaluation conducted at ELINJ from a periodic observation of teaching sessions, and from the focus group interviews. In this program, the teachers were observed regularly by three different observers in the consecutive modules. The observers focused mainly on writing their comments on teachers' performance according to the 11 identified observation dimensions. The observers were given a question for each dimension to help them write detailed feedback. For the purposes of this discussion, the classroom observation activities have been divided into three stages: stage one, presentation and active learning; stage two, management of the learning environment and the last stage, interaction and reflection. Each stage included more than one classroom dimension; extracts from the peer observations and external observer have been used to support the argument.

Feedback from the selected teachers on the evaluation programme was also gathered through the focus group interviews. This feedback was then analyzed and presented insofar as to help to encourage teachers to be more conscious of their practices. It was similarly meant to help teachers to refine their teaching and learning abilities by the time of the next evaluation and to elucidate the program procedures. The interview questions revolved around three main themes, teachers' (interviewees') reflection on the new development program, the changes made to the working environment, and their suggestions for further development of the evaluation program.

\section{Classroom Observation}

(1) Planning: Did the teacher define the objectives of the lesson? If so, how clearly?

The peer observation reports showed that all the instructors wrote the lesson goals on the board for their students, and some of them read them aloud to the students. However, the third observation reports made by the external observer showed that all the teachers were writing the goals on the board in a very routine way and moving over them very quickly. Also the instructors were not encouraging the learners to discover the relation between the lesson's goals and the overall objectives of the unit. According to Nunan (2004), the learning process can break down if this triggering stage is moved over too quickly.

(2) Sequencing: Was the presentation smooth and sequenced? Support your judgment with specific examples.

There was an obvious development in the observers' descriptions of their peers' lessons during the course of the evaluation program. On the first peer observation visit, most of the observers gave only short descriptions. For example, on his first visit teacher D. commented, "The transition was smooth. Teacher E. linked the previous lesson to today's lesson successfully". However, on the second visit, the same instructor, Teacher D. wrote, "Mr M. delivered the lesson with two identified stages... first, the teacher introduced the topic... then he drew a table with two headings... he divided the students into groups... the students responded well to the teacher's instructions and they answered [his questions]...". This example showed a development in the awareness and skills of this observer, since he was able to detect and report details in the teaching practice of his peer.

(3) Instructions/explanation: Did the teacher explain the class material in an understandable way? Provide details.

The results showed that the teachers' awareness of good classroom practices developed over the course of the evaluation period. On the second classroom visit the instructors were able to give more critical feedback 
than on their first visit. For example, teacher A. wrote, "...could have explained specific core ideas and concepts such as job announcements...more clearly". Teacher H. wrote, "owing to students' low level he should have made sure that all learners were following when he moved from one activity to another".

(4) Motivation: To what degree did the teacher motivate and ensure student participation?

The observation notes showed that there were differences between how teachers and the external observer interpreted the term "motivation". The teachers appeared to think that motivation meant getting the students to participate by asking them more questions and getting them to answer. Teacher B. wrote in praise of teacher F. that, "he constantly asks students for their comments on the pictures". Teacher D. also wrote, "Mr. K divided the students into groups and encouraged their participation by saying 'very good'...". However, the external observer's comments showed that none of the teachers were promoting learning through presenting challenging tasks that required the learners to listen to each others' ideas, or to describe and articulate their thinking and reasoning. The external observer made the following comment on Teacher C.'s class: "students are answering the questions without showing any real interest that could be seen by the instructor... He should get them motivated by asking more argumentative questions to encourage them to speak, or make the lesson more meaningful by finding a link between the classroom activities and the students' context". Purposeful learning is an important factor in stimulating learners' intrinsic motivation (Lin \& Mackay, 2004).

(5) Time management: Did the teacher use class time effectively? How?

There was an obvious improvement in the teachers' time management between the first and third classroom observations. Most of the teachers who received negative comments on the first visit had managed to overcome the problems by the second and third observations. Only one teacher, teacher G., seemed to have a problem with time management on all the three visits as most of his class time was given over to teaching grammar. It is important to note that peer observation is a two-way learning process. Teachers learn from their peer feedback and they also learn from observing and writing feedback.

(6) Whiteboard and visual aids: Comment on the teacher use of the white board and other visual media.

Over time the instructors showed improvement not only in the use of classroom facilities, but also in the skills they needed to use them effectively. At first, most of the teachers were using projectors to motivate the students. However, by the second and third observations, according to their peers' comments, it was clear that they had become more aware of the use of the whiteboard, which was, along with other visual aids, used more effectively. Regarding his second visit, teacher H. wrote "Mr. A's [use of the] whiteboard was very structured; he was successful in teaching the comparative concept using the pictures and images on his laptop".

(7) Space management: Do you think the seating arrangement facilitated learning? Describe and comment on the seating plan.

The reports showed that the seating was not an issue and that most teachers arranged their classrooms in a U-shape. All the notes stated that both the teacher and the white board were clearly visible to all students.

The last part of the observation report was the evaluation of the level of interaction between teacher and students, and of the process of reflection carried out by the teachers at the end of the lesson. The observation reports showed that the classrooms were all teacher-centred and that the students' role was mainly passive. Students were not asked to give their opinions on any of the lesson content. According to Cotterall and Murray (2009) and Cotterall (2000), listening to learners and observing their interactions with each other give teachers a better idea of when and how to intervene. This method gives learners a more active role and helps teachers to 
assess their learning (Cotterall, 2000). The observers' reports showed that classroom interaction consisted simply of the teachers answering all the questions raised by the students, which were mainly inquiries about the activity they were engaged in. Teacher F. commented, "Mr. E. has a good rapport with his students; he answered all their questions using the appropriate, easy and direct language... [his] facial expressions and attitude were very encouraging". Teacher B. also wrote concerning his second visit to teacher $\mathrm{H}$. "He demonstrated respectful behaviour toward his students... his sense of humour helped to make his classroom a comfortable learning environment".

Before the end of the class, the teachers summarized the lesson to their learners. But most of the teachers' summaries were simply reading aloud from the white board or their notes, without any student involvement. This was a common feature in both observation phases. For instance, teacher G. wrote, "Mr. D. wrote the main points on the board...", and when teacher G. was observed he did the same thing. Teacher F. wrote: "Mr. G. was successful in drawing a table and he summarized the ideas...". By contrast, the external observation reports showed that the teachers lacked knowledge about the importance of lesson summaries and reflection. Encouraging learners to summarize develops their language skills, and reflection is important to develop learners' critical and communication skills and to make learning more meaningful (D. Willis \& J. Willis, 2007). Learners should be given the opportunity to reflect and comment on their learning. They should be encouraged to find a connection between the lesson at hand and other tasks within the curriculum, or with the broader picture outside the school (Lin \& Mackay, 2004).

The analysis of the observation reports, including the external observation notes, showed that the teachers' performance had developed, and that the observation components had helped to raise the teachers' awareness of good practice. Developments in the management of the classroom environment, which included time management, the use of the white board and other visual aids, and space management, was more obvious than in the other classroom stages: the stage of presentation and active learning, and the interaction and reflection stage. These differences in degrees of development could be a result of the type of training these teachers had received in the past. The skills of time management and space management are easy for teachers to acquire: They are observable skills. So it was easy for teachers to see what their peers were doing and to learn from each other. However, other skills, such as motivation and reflection are abstract concepts which may require extensive training before it is possible to observe significant improvements in teachers' performance.

\section{Interview Analysis}

The interview questions centred on three main themes: reflecting on the new evaluation program (strengths and weaknesses), the changes made to the working environment, and changes desired to be seen in the development of the evaluation program.

(1) Program evaluation (strength/weakness): The data obtained from the teachers' focus group interviews indicated that all participants thought the program was successful and was a good opportunity for them to develop and learn from the feedback. Teacher C. commented, "The feedback I received was very helpful and fruitful", while teacher E. said "The external observer informed me that the time devoted to activities in class was longer than it should be; I wouldn't have known that if he had not told me". With regard to the strength of the program, all the teachers agreed that the "the presentation idea was excellent", as teacher H. said. They liked the presentation idea as part of the development program, since it gave them the opportunity to share ideas, beliefs, and opinions on how some skills, such as reading or writing, could be thought about, and to learn 
from other teachers' experiences. Another advantage from the teachers' point of view was the recording of their classes. Some teachers said that they were uncomfortable with the video at the beginning. However, by the end of the programme they had found that video recording of the classes gave them the opportunity to watch their performance and work on improving their teaching, especially when they realised these recordings would be confidential.

On the other hand, the teachers stated that the time factor was a constraint. They said 15 weeks - the length of the development program - was too short for significant improvements to be noticeable in their performance. According to the teachers, three weeks between each observation did not give them enough time to reflect on their performance. Teacher E. said, "the programme should be run over the whole academic year, and at least 7 weeks should be allowed between each observation". The teachers thought that the observation form was distracting, with the large and comprehensive number of criteria it included! Teacher G. said, "it is very difficult as an observer to observe all the points mentioned in the form in a 50-minute class", and teacher F. added that, "as a teacher it is also difficult to teach when you have in mind the number of criteria you are being observed on". A very important issue that most of the teachers were reluctant to talk about during the interviews was the report feedback. The interview data revealed that all the teachers felt embarrassed about giving very negative feedback on their colleagues' performance, because, as some stated, it could cause them to lose their jobs. However, they were all assured that these reports would not be used for any purpose other than development. Teacher A. said, "observing someone's teaching is a subjective process; what I think is the right way to teach could be considered something else by my colleague". In fact, this comment raises the issue of the importance of teacher training being conducted according to a good teaching model.

(2) The changes in the environment: The teachers claimed that the program encouraged positive behavior patterns among them. All teachers were involved in the program, each participant played one of the roles; a presenter, observer and observed, and all of them discussed and offered their opinions on the teaching process. This working environment motivated the teachers and made them more confident. Teacher N. said, "in the past none of us participated or shared his opinion, and this [the opportunity to do this during the program] created a belonging environment I suggest either 'a supportive environment' or 'a sense of belonging'". Teacher B. said, "I have become more confident about discussing my weaknesses with my colleagues or discussing their weaknesses", and teacher I. added: "coming from different cultures and teaching backgrounds, this is a good opportunity for all of us to learn and maybe understand each other". A very interesting comment was made by teacher E., who said in reference to the presentation sessions: "this program made me open books and read after a long time".

(3) Suggestions for developing the current program: The teachers suggested that the new version of the program should include workshops given by professionals and should focus on topics related to teaching methodology and learners' motivation. The evaluation program should consider external factors which could affect implementation, and therefore affect teachers' performance, such as changes in exam dates, or holidays in the middle of the semester. They suggested that more meetings between the teachers and the program directors had to take place during the academic year, especially after each phase of the evaluation programme, to listen to each other's comments, and respond to changes. Finally, the teachers talked about rewards and appreciation as very important factors in their development. Teacher M. said, "we need to receive letters or a certificate for our participation in this program or any activities we participate in", while teacher C. said, "why don't you give rewards for teachers who show improvements?". However, teacher L. said, "a good method to 
show appreciation is to give the good teacher a position or responsibility". These teachers are expatriates; therefore, certificates of participation and letters of appreciation could help them in their search for better jobs in the future.

\section{Study Limitations, Implications, and Recommendations}

With the growing importance of teacher learning in research-based studies, the use of peer observations as the only evaluation instruments could not capture teachers' professional development experiences comprehensively, particularly as teachers in this study were not provided with specified teaching materials and guidance. Focusing on and comparing teachers' transformative versus transmissive learning and development experiences could be subtle in this regard based on the limited population number. Furthermore, to corroborate any results indicative of improvement in teachers' practices may rest to a great extent on their conceptions and actual engagement in professional development practices. In the same context, themes such as teachers' professional development needs and organizational versus individual development priorities are not raised in the analysis process of the observation reports. Referring to these themes would have informed the discussion of teacher development propensities at ELINJ, and raised a comparison with other contexts of predefined evaluation programs.

At the level of study implications, this study helped in probing collaborative work among teachers. They were engaged in participatory evaluation, where the teachers' experiences feed back to their evaluation comments. Additionally, investigating teacher development led to raising the standards of teachers' expectations in terms of their performance and shed light on their classroom practices. The process of meaning-making in the study was enriched by the disparate backgrounds, positions, and roles held by participants. Similarly, the direct effect of teachers' development on student achievement was detected in concrete terms, leading in this way to consider the potential effect of teacher professional development on learning and to promote a high quality of development, where the student learning was considered as an integral standard of evaluation. In fact, introducing a teacher-based evaluation program in this study prepared the ground for an established program where consensus over the criteria of development could be sustained and a clear vision of professional development could be transmitted to teachers. Establishing a common evaluation framework is susceptible to shape and enhance teacher learning and development opportunities.

This study sought to generalize reflective evaluation among teachers. Such practice, when based on adequate instruments, is conducive to augment teachers' learning opportunities and to gauge their professional development effectiveness. By reference to other studies (Desimone, 2009), discrete measures and methodology need to be set in place to scrutinize the effect of teacher professional development on teachers' performance and student learning. This practice is prominent insofar as it targets and unveils some classroom practices, and documents concrete instances of teacher learning opportunities created within and outside the class. At a more advanced level, contextualizing teacher development with organizational development is an urgent need to secure a decent standard of educational quality. The call for a system of evaluation to be established in order to assess teachers' practices and assist them to improve their performance in cases of gaps should rest upon an interaction between predefined evaluation programs and self-reflective strategies used by individual teachers. Promoting teacher professional development in the Saudi context necessitates that collaborative techniques, such as peer observation, and individual strategies, comprising lesson planning, and journal writing, should be part of an established system toward investigating core learning features in teacher 
professional development and increasing teacher and education effectiveness.

\section{Conclusion}

Across all disciplines, teachers' professional development and ongoing assessment require teachers, peers and administrators to engage in greater written and oral discussions where feedback is given and taken within an enriching environment. With the results of this study, such practices are highlighted because they represent significant teaching and learning demands. The content, performance and demands of teacher evaluation would augment the challenges for English language teaching. Teacher preparation and professional development programs need to be designed to support professional development and enhancement of the instructional performance expected of teachers. And as new curricula are being introduced nowadays, educators will need to understand the shifts required in teaching, and then they will need to have hands-on opportunities for teachers to acquire teaching strategies that respond to these shifts. To investigate this, further research is needed in this area.

\section{References}

Aburizaizah, S. (2013). Introducing content and language-integrated learning at a Saudi Arabian University. In R. Wilkinson and M. L. Walsh (Eds.), Integrating content and language in higher education: From theory to practice (pp 101-116). Switzerland: Peter Lang Edition.

Aburizaizah, S. (2014). Developing a framework for classroom lesson delivery to improve English teachers' performance in the foundation year programme at a Saudi University. English Language Teaching, 7(1), 1-8. doi:10.5539/elt.v7n1p1

Barduhn, S. (2002). Decision making during teaching. Retrieved from http://works.bepress.com/susan_barduhn/10/

Barnstein, D. (2008). Applying a classroom model to the evaluation of professional work. Teaching Matters, 12(1), 1-8.

Cotterall, S. (2000). Promoting learner autonomy through the curriculum: Principles for designing language courses. ELT Journal, 54(2), 109-117.

Cotterall, S., \& Murray, G. (2009). Enhancing metacognitive knowledge: Structure, affordances and self. System, 37(1), 34-45.

Cowan, J., \& Westwood, J. (2006). Collaborative and reflective professional development. Active Learning in Higher Education, 7(1), 63-71. doi:10.1177/1469787406061149

Cuddapah, J. L., \& Clayton, C. D. (2011). Using Wenger's communities of practice to explore new teacher cohort. Journal of Teacher Education, 62(1), 62-75. doi:10.1177/0022487110377507

Danielson, C., \& McGreal, T. L. (2000). Teacher evaluation: To enhance professional practice. Alexandria, VA: Association for Supervision and Curriculum Development.

Desimone, L. M. (2009). Improving impact studies of teachers' professional development: Toward better conceptualizations and measures. Educational Researcher, 38(3), 181-199. doi:10.3102/0013189X08331140

Dierking, R. C., \& Fox, R. F. (2013). Changing the way I teach: Building teacher knowledge, confidence and autonomy. Journal of Teacher Education, 64(2), 129-144. doi:10.1177/002248711462893

Dörnyei, Z., Csizér, K., \& Németh, N. (2006). Motivation, language attitudes and globalisation: A Hungarian perspective. Clevedon, England: Multilingual Matters.

Edge, J. (Ed.) (2001). Action research. Alexandria, VA: Teachers of English to Speakers of Other Languages (TESOL), Inc..

ELINJ. (2014). Retrieved February 25, 2014 from http://eli.njb.kau.edu.sa/Default.aspx?Site_ID=974andLng=EN

Erickson, H. L., \& Lanning, L. A. (2014). Transitioning to concept-based curriculum and instruction: How to bring content and process together. Corwin Press Publisher.

Erlam, R. (2015). I'm still not sure what a task is: Teachers designing language tasks. Language Teaching Research, 1-21. doi: $10.1177 / 1362168814566087$

Florian, L. (2012). Preparing teachers to work in inclusive classrooms: Key lessons for the professional development of teacher educators from Scotland's inclusive practice project. Journal of Teacher Education, 63(4), 275-285. doi:10.1177/0022487112447112

Freeman, D., \& Freeman, Y. (2004). Essential linguistics: What you need to know to teach reading, ESL, spelling, phonics, grammar. Heinemann: Portsmouth, NH. 
Gao, X. A., \& Xu, H. (2014). The dilemma of being English language teachers: Interpreting teachers' motivation to teach, and professional commitment in China's hinterland regions. Language Teaching Research, 18(2), 152-168. doi:10.1177/1362168813505938

Gosling, D. (2002). Models of peer observation of teaching. LTSN: Generic Centre.

Grossman, P., Loeb, S., Cohen, J., Hammerness, K., Wyckoff, J., Boyd, D., \& Lankford, H. (2010). Measure for measure: The relationship between measures of instructional practice in middle school English Language Arts and teachers'value-added scores. (NBER Working Paper No. 16015)

Hammersley-Fletcher, L., \& Orsmond, P. (2005). Reflecting on reflective practices within peer observation. Studies in Higher Education, 30(2), 213-224.

Harris, K. R., Lane, K. L., Graham, S., Driscoll, S. A., Sandmel, K., Brindle, M., \& Schatschneider, C. (2012). Practice-based professional development for self-regulated development in writing: A randomized controlled study. Journal of Teacher Education, 63(2), 103-119. doi:10.1177/0022487111429005

Henderson, C., \& Rosenthal, A. (2006). Reading questions-encouraging students to read the text before coming to class. Journal of College Science Teaching, 35(6), 46-54.

Hiver, P. (2013). The interplay of possible language teacher selves in professional development choices. Language Teaching Research, 17(2), 210-227. doi:10.117711362168813475944

Hokka, P., \& Etelapelto, A. (2014). Seeking new perspectives on the development of teacher education: A study of the Finnish context. Journal of Teacher Education, 65(1), 39-52. doi:10.1177/0022487113504220

Judah, M. L., \& Richardson, G. H. (2006). Between a rock and a very hard place: The ambiguous promise of action research in the context of state mandated teacher professional development. Action Research, 4(1), 65-80. doi:10.1177/1476750306060543

Koutselini, M. (2008). Participatory teacher development at schools: Processes and Issues. Action Research, 6(1), 29-48. doi:10.1177/1476750307083718

Kumaravadivelu, B. (2006). Understanding language teaching: From theory to post method. Mahwah, New Jersey: Lawrence Erlbaum Associates.

Lieberman, A., \& Mace, D. P. (2010). Making practice public: Teacher learning in the 21st century. Journal of Teacher Education, 61(1-2), 77-88. doi:10.1177/0022487109347319

Lin, M., \& Mackay, A. (2004). Thinking through modern foreign languages. Cambridge: CUP.

Loughran, J. (2014). Professionally developing as a teacher educator. Journal of Teacher Education, 65(4), $271-283$. doi: $10.1177 / 0022487114533386$

McMeniman, M., Cumming, J., Wilson, J., Stevenson, J., \& Sim, C. (2003). Teacher knowledge in action: The impact of educational research. Australia: Department of Education, Training and Youth Affairs.

Mirra, N., \& Morrell, E. (2011). Teachers as civic agents: Toward a critical democratic theory of urban teacher development. Journal of Teacher Education, 62(4), 408-420. doi:10.1177/0022487111409417

Nunan, D. (2004). Task-based language teaching. Cambridge: Cambridge University Press.

Richards, J. C. (2001). Curriculum development in language teaching. New York: Cambridge University Press.

Sargent, T. C., \& Hannum, E. (2009). Doing more with less: Teacher professional learning communities in resource-constrained primary schools in rural China. Journal of Teacher Education, 60(3), 258-276. doi:10.1177/0022487109337279

Seldin, P. (1998). How colleges evaluate teaching: 1988 vs. 1998. AAHE Bulletin, 50(7), 1-7.

Swars, S. L., Meyers, B., Mays, L. C., \& Lack, B. (2009). A two-dimensional model of teacher retention and mobility: Classroom teachers and their university partners take a closer look at a vexing problem. Journal of Teacher Education, 60(2), 168-183. doi: $10.1177 / 0022487108329116$

Tomlinson, C. A. (2003). Deciding to teach them all. Educational Leadership, 61(2), 6-11.

Tunney, J., Goldsmith, L. T., Seago, N., \& Van Es, E. A. (2014). A framework for the facilitation of teachers' analysis of video. Journal of Teacher Education, 65(4), 340-356. doi:10.1177/0022487114534266

Williams, J. (2014). Teacher educator professional learning in the third space: Implications for identity and practice. Journal of Teacher Education, 65(4), 315-326. doi:10.1177/0022487114533128

Willis, D., \& Willis, J. (2007). Doing task-based teaching. Oxford: Oxford University Press.

Yeboah, K. A., \& James, W. (2012). Transformational teaching experience of a novice teacher: A narrative of an award-winning teacher. Adult Learning, 23(4), 170-177. doi:10.1177/1045159512457354 